\title{
Semantics, Grammar and Prosody of parentheticals introduced by the Subordinator kak 'as'
}

\author{
Podlesskaya V. I. \\ Russian State University for the \\ Humanities, Moscow, Russia \\ vi_podlesskayalil-rggu.ru
}

\author{
Pozhilov Ju. M. \\ Russian State University for the \\ Humanities, Moscow, Russia \\ yuriko.pozhiloveyandex.ru
}

\begin{abstract}
Based on data from the multimedia subcorpus of the Russian National Corpus, the paper addresses syntactic, sematic and prosodic features of the particular type of quotations with the reporting frame headed by the subordinator kak 'as' (kak skazal mne staryj rab pered tavernoj...). Our data show mixed evidence regarding the parenthetical status of the construction. On the one hand, typically for parentheticals, its function is clearly pragmatized, since it expresses speaker's attitude towards the quote. On the other hand, typical parentheticals have only loose syntactic connection with their "host", while the kak-phrase is introduced by the subordinator and has the form of the standard adverbial clause. Further on, while typical parentheticals are characterized by grammatical and prosodic reduction, grammatical and prosodic restrictions operating in the kak-phrase are optional and context (e.g., word order) sensitive. The kind of data we present supports the approach to parenthesis that doesn't favor either/or decisions, but rather is based on multifactorial analysis that considers the whole range of possible parameters and isolates their observed language-specific clusters.
\end{abstract}

Keywords: spoken discourse, Russian, prosody, parenthesis

DOI: $10.28995 / 2075-7182-2021-20-546-559$

\section{Семантика, грамматика и просодия вводно-союзных конструкций по данным мультимедийного подкорпуса НКРЯ}

\author{
Подлесская В. И. \\ РГГУ, Москва, Россия \\ vi_podlesskaya@il-rggu.ru
}

\author{
Пожилов Ю. М. \\ РГГУ, Москва, Россия \\ yuriko.pozhilov@yandex.ru
}

\begin{abstract}
Аннотация
В данной работе на материале мультимедийного подкорпуса НКРЯ рассмотрены синтаксические, семантические и просодические свойства авторской ремарки, вводящейся союзом «как» (как сказал мне старый раб перед таверной...). Наши данные показывают, что такие конструкции могут демонстрировать разную степень парентетичности. С одной стороны, они достаточно прагматикализованы, так как в их значении отражена позиция говорящего по отношению к цитате, что свойственно для парентез. С другой стороны, типичные парентезы теряют синтаксическую связь с «главной» клаузой, в отличие от как-фраз, которые вводятся союзом и имеют форму стандартной обстоятельной клаузы. Более того, в то время как стандартные парентезы характеризуются грамматической и просодической редукцией, в как-фразах грамматические и просодические изменения опциональны и контекстуально зависимы - в частности, они чувствительны к порядку слов. При работе с такими данными мы считаем нужным отказаться от бинарного противопоставления в пользу многофакторного анализа парентезы, позволяющего учитывать все многообразие исследуемой зоны.

Ключевые слова: устный дискурс, русский язык, просодия, парентеза
\end{abstract}




\section{1 Постановка задачи}

Предмет исследования в этой работе - конструкции, в которых авторская ремарка вводится в клаузе с союзом как ${ }^{l}$ :

(1) Как говорил Александр Иванович Гериен/ знакомство с иностранием для русского человека/ это в некотором роде повышение в чине. [Владимир Меньшов, Марина Мареева. Зависть богов, $\kappa / \phi(2000)]^{2}$

Рассматриваемый нами класс конструкций относится к так называемым «вводно-союзным», согласно определению Е.В.Падучевой (1996: 321-334). В принципе, в вершине клауз, вводимых союзом как в данной функции, возможны глаголы разных семантических классов, например, глаголы мнения (как считают британские ученые), однако в данной работе мы ограничимся только глаголами речи (понимаемыми, впрочем, достаточно широко - как глаголы порождения текста, т.е. не только говорить, но и, например, писать, учить, велеть - в соответствии с номенклатурой семантических классов, принятой в НКРЯ). Мы постараемся показать, что как-ремарки на разных языковых уровнях - прагматическом, грамматическом и просодическом - демонстрируют симптомы парентезы, т.е. редукции, или ослабления их вклада в пропозициональное и истинностное значение высказывания; ср. сходные понятия «десентенциализации» (desententialization, Lehmann 1988), или «понижения в ранге» (deranking, Cristofaro 2003), в русистике понятие редукции успешно применяется к анализу вводных единиц Г.И.Кустовой (2020:18).

Ядро наших данных составляют примеры из Мультимедийного подкорпуса НКРЯ (МУРКО). Для инструментального изучения просодии из видеофайлов выдачи МУРКО извлекались аудиофайлы и подавались на вход анализатора PRAAT (Boersma, Weenink 2021). При анализе грамматики и семантики мы прибегаем также к данным из других подкорпусов НКРЯ, прежде всего, устного.

Изложение будет построено так: в разделе 2 мы остановимся на семантике конструкций с какремаркой, в разделе 3 обсудим их структурные свойства. В разделе 4 мы продемонстрируем основные паттерны, которым следует просодическая реализация конструкций с как-ремаркой. Эти три раздела не герметичны: с одной стороны, многие грамматические свойства этих конструкций объясняются их семантикой, а с другой - просодия неразрывно связана и с грамматикой, и семантикой - так, локализация и направление движения тона во фразовых акцентах чувствительны к порядку слов и референциальному статусу именных групп, обозначающих локуторов. В разделе 5 мы подведем итоги и попытаемся ввести полученные результаты в общий контекст исследований парентезы как лингвистического феномена.

\section{2 Семантика конструкций с как-ремаркой}

Как было убедительно показано Е.В.Падучевой (1996: 327-328), «вводно-союзная конструкция ... используется для передачи чужого мнения, которое служит говорящему основанием для его собственного суждения», или для передачи чужого способа выражения, причем в этом случае «говорящий отстраняется от способа выражения, хотя присоединяется к самой мысли», а автор цитаты обычно бывает «авторитетным» (как указывает академик Виноградов). Наши корпусные данные показывают, что ссылка на авторитет, как в примере (1), - это частая, но не единственно возможная функция таких конструкций. Другой распространенный случай - это отсылка к высказыванию локуторов или иных, третьих лиц - участников беседы:

(2) Я сам из Челябинска/ вот как Антон сказал/ из благополучного Челябинска [Ю.Б. Черкасов. Выступление на первомайском митинге в Новосинеглазово (2017)]

\footnotetext{
1 Исследование поддержано грантом РНФ 17-18-01184

2 Примеры даются в том графическом формате, в котором они приводятся в соответствующем подкорпусе НКРЯ, за исключением случаев, где мы добавляем просодическую разметку. Эти случаи отдельно оговариваются.
} 
Если в как-фразе вводится высказывание от первого лица, то возникает дополнительный оттенок смысла - говорящий оправдывает возможную нестандартность цитаты своим авторским приоритетом, а также тем, что это цитата вводится как уже апробированная:

(3) Ой/ ну это тяжело всё. Я понимаю/ что я в своём возрасте щас открываю/ как я говорю/ хайло. [Валентина, жен, начальник отдела кадров] Ну это да! [Разговоры в офисе (2008) // Из коллекиии НКРЯ]

(4) Сейчас приезжаешь куда-нибудь в Америку/ извините за снобизм/как я говорю своим студентам/в Гарварде идёшь там по стеллажам в хранении - наслаждение одно ходить по стеллажам [Михаил Булгаков. Программа "Гордон" (НTВ) (2003)]

Как-фраза может отсылать и к массовому узусу, это особенно часто случается, если она строится с использованием возвратного пассива, безличного, неопределенно-личного или иного «анонимизирующего» формата (как говорят у нас в Одессе, как поётся в известной песне) ${ }^{3}$. Инвариантом отсылки к высказыванию авторитетного источника, отсылки к высказыванию участника беседы и к массовому узусу можно считать отсылку к такому высказыванию, которое, по мнению говорящего, имеется не только в его собственной базе знаний, но и в базе знаний иных членов языкового коллектива.

\section{3 Грамматика конструкций с как-ремаркой}

Базовое значение конструкции - предъявление некоторого выказывания как уже имеющегося в общем поле знаний - помогает объяснить некоторые грамматические ограничения на какремарку.

\section{1 Ограничения на форму глагола}

Имеются ограничения на грамматическую форму глагола речи в ремарке.

Это, во-первых, ограничения на грамматическое время. Глаголы совершенного вида имеют только форму прошедшего времени, глаголы несовершенного вида могут использоваться и в презенсе, передавая узуальное значение, значение одновременности с событиями главной клаузы (происходившими в прошлом) или значение praesens historicum, (5) (помимо того, что часть вхождений в форме настоящего времени обеспечивается упоминавшимися выше «анонимизирующими» формами):

(5) Закончилось все тем, что в 1742 году «князя-черепаху» свалил апоплексический удар, и он скончался, как пишет современник, «от семейных неприятностей». [И. Грачева. Твердость металла и нежность иветка // «Наука и жизнь», 2007]

Использование будущего времени оказывается практически заблокированным. Имеющиеся единичные примеры могут интерпретироваться как будущее в прошедшем:

(6) То есть было безлюбовное отношение к земле/ не моя земля. Сегодня попользовался и отдам. Как потом скажет один русский философ/ военнопленная земля. [Юрий Пивоваров. Традиичи русской государственности и современность. Проект Асаdетіа (ГТРК Культура) (2010)]

Как-ремарки употребляются и во «вневременных» контекстах, например, в контекстах со снятой утвердительностью. В этих случаях типично употребление глагола речи в сослагательном наклонении ${ }^{4}$ :

\footnotetext{
3 «Анонимизирующие» конструкции и, в особенности, как-фразы с некоторыми глаголами речи в форме возвратного пассива склонны к прагматизации вплоть до превращения в дискурсивный маркер с хезитативным или аппроксимативным значением. Мы благодарны рецензенту, обратившему наше внимание на то, что в качестве такого дискурсивного маркера употребляется конструкция как говорится.

${ }_{4}^{4}$ Рецензент справедливо заметил, что в подобных контекстах допустимо и будущее время глагола. В примерах, которые приводит рецензент, снятая утвердительность подкрепляется и «анонимизирующими» местоимениями некий, всякий: Но почему-то мне показалось сегодня, что этот розовато-золотой, дымчато-голубой зимний день требует
} 
(7) И работа его над этим текстом закончилась - ну/ "автор умер"/ как сказал бы Ролан Барт. [Рождение художественного текста. Программа "Гордон" (НТВ) (2003)]

Во-вторых, как показали проницательные наблюдения Е.В.Падучевой (1996: 327-328) и Г.И.Кустовой $(2020: 18)$ в как-ремарке - как и во многих вводных фрагментах - не допускается общее отрицание (*как не говорил Александр Иванович Гериен).

В-третьих, как-ремарка, не являясь по своему синтаксическому статусу главной клаузой, не способна быть самостоятельным носителем иллокутивной силы. Более того, использование какремарки затруднено в составе вопросов и директивов, хотя и не запрещено полностью:

(8) И неужели, как говорила Лазура, жизнь есть вечная перемена различных образов? [Н. П. Вагнер. Сказки Кота-Мурльки (1872)]

(9) Так шо/ козаки/ вручить шашку Игорю Владимировичу/ а? Любо! Так шо/ как говорится/ прими в знак любви и уважения. [Леонид Бараи, Олег Фомин, Ростислав Хаит, Сергей Петрейков. День выборов, к/ф (2007)]

\section{2 Ограничения на порядок слов}

Важнейшим структурным ограничением, действующим в как-ремарке, является ограничение на порядок слов: если подлежащее ремарки (субъект речи = автор цитаты) выражено полной именной группой, то предпочтительна инверсия подлежащего и сказуемого. Это правило действует независимо от того, расположена ли ремарка до, после или внутри цитаты:

(10) Как мне сказал знакомый астроном/ количество нейронных связей в мозгу больше/ чем звёзд во Вселенной [Татьяна Черниговская. Как мы мыслим. Разноязычие и кибернетика мозга. Лекиии Полит.ру (2009)]

(11) В этом залог нашей победы. Как говорили шведы под Полтавой. [Владен Бахнов, Леонид Гайдай. Спортлото-82, к/ф (1982)]

(12) Вообще/ э/ мир/ как говорили греки/ начался из Хаоса/ но потом родил Космос. [Мир как вакуум. Программа "Гордон" (НТВ) (2001)]

Если же подлежащее ремарки - местоимение, то сохраняется прямой порядок ${ }^{5}$, ср. невозможность инверсии *как говорил я в следующем примере:

(13) Ведь Солние/ как я говорил/не единственная/так сказать/звезда/ есть вещчество от других звёзд/ есть межпланетная плазма. [Лев Зеленый. Солнечная империя. Проект Acadeтіа (ГТРК Культура) (2010)]

Данное различие естественно связать со степенью актуализованности референта-говорящего. Это предположение получает дополнительное подтверждение, если посмотреть на те редкие контексты, в которых прямой порядок облегчен и для полных именных групп: это, в частности, те как-ремарки, где референт-говорящий актуализован как один из участников беседы, см. (14) или как один из членов ассоциированного множества - например, входит в составляющую с контрастивным значением, см. (15), где контрастивную интерпретацию обеспечивает частица ещё (контраст в (15) усилен еще и самоисправлением говорящего, заменяющего инверсивный порядок на прямой - как говорил... как еще классики марксизма говорили):

\footnotetext{
от меня, как скажет некий политик через двадцать лет, «симметричного ответа»; купец, как скажет всякий, кто имел с ним дело, жил обманом...

${ }^{5}$ В обследованных нами данных МУРКО это правило практически не имеет исключений, однако, как верно указал рецензент, инверсия местоимения и глагола возможна: если в как-фразе имеется тяжелая группа, которая может приобретать рематический статус, она перемещается в крайнюю правую позицию, а местоимение помещается после глагола перед этой группой: Нет, нет, она не забыла его, как говорил он ночью в клинике бедному Ивану. По-видимому, такие построения не очень свойственны устной речи, и этим объясняется отсутствие подобных примеров в нашей выборке.
} 
(14) Это соответствует ну ультрафиолету/как Володя говорил/ это пятьдесят тысяч градусов по другой шкале/ в другом формате. [Динамическая нестабильность воды. Программа "Гордон" (НTВ) (2003)]

(15) Вот по сути дела в этот момент оказалось/ что люди/ создающие этот продукт/являются не рабочими/которые должны прийти/как говорил... как ещё классики марксизма говорили/ прийти и наняться к капиталисту/ а он является человеком/который создаёт от начала до кониа весь продукт. [Класс интеллектуалов. Программа "Гордон" (НТВ) (2003)]

Более глубокий теоретический и типологический анализ инверсии в как-ремарке выходит за рамки данной работы, однако мы считаем уместным указать на следующие три обстоятельства, демонстрирующие системность обнаруженного нами явления. Первое. Инверсия в клаузах, вводимых сравнительными союзами, наблюдается в целом ряде языков, причем, как правило, такие клаузы демонстрируют те или иные симптомы парентезы, ср. так называемые as-parentheticals в английском языке Mary was reading Moby-Dick, as could have been her brother; данные английского, датского, тайского, испанского, ирландского и др. приводятся, inter alia, в Potts 2002, LaCara 2016. Второе. Инверсия в авторской ремарке наблюдается и в стандартных конструкциях с прямой речью, если ремарка вынесена в постпозицию к цитате, ср. «Сегодня занятия не будет!» сказал Петя. Более того, в отличие от как-ремарки, в постпозитивной ремарке в формате главной клаузы инверсия сохраняется, даже если подлежащее местоимение, ср. «Сегодня занятия не будет!» - сказал он, но не * «Сегодня занятия не будет!» - он сказал. И опять же, препозиция сказуемого в таком контексте наблюдается не только в русском языке, ср. англ. 'You're the Best Bear in All the World,' said Christopher Robin soothingly. И, наконец, третье. В русском языке имеется целый арсенал конструкций с выдвижением глагола влево. В работах Т.Е.Янко (2001:197-229, inter alia) детально проанализированы коммуникативные стратегии, которые кодируются с помощью различных вариантов такого выдвижения. Как кажется, с как-ремаркой также ассоциированы определенные ограничения на коммуникативную структуру. В частности, в конструкциях с как-ремаркой рематический статус имеет сама цитата, тогда как ремарка является либо темой, либо парентетической составляющей. В следующем разделе мы продемонстрируем некоторые просодические подтверждения этому тезису.

\section{4 Просодия конструкций с как-ремаркой}

В предыдущих разделах мы увидели ряд симптомов семантической и грамматической редукции как-ремарки, или, иначе говоря, по сравнению с функционально близкими главными клаузами, здесь налицо ограничения семантических и грамматических свобод: как-ремарка может вводить не любую цитату, а только ссылку на текст, ассоциированный с эпистемической оценкой говорящего (предъявляемый как имеющийся в общем поле знаний), в как-ремарке невозможно отрицание, ограничены формы глагольных времен и типы иллокуций, действуют особые правила порядка слов. В этом разделе мы покажем, что в как-ремарке наблюдается и просодическая редукция, однако с этой точки зрения как-ремарки неоднородны: степень их просодической редукции тесно связана с их позицией в синтаксической структуре предложения и, шире, с их позицией в локальной дискурсивной структуре. Рассмотрим прототипические паттерны реализации конструкций с как-ремаркой.

\section{1 Как-ремарка перед цитатой}

Рассмотрим два примера препозитивной как-ремарки - в (16) автор выражен полной именной группой, в (17) - местоимением. Для каждого примера приведем сначала его полную графическую форму, как она дана в МУРКО, далее - транскрипцию части примера с разметкой движения тонов и локализацией фразовых акцентов ${ }^{6}$ и интонограмму в формате анализатора PRAAT:

\footnotetext{
${ }^{6}$ Для указания на направление движения тона иконически используются знаки «/», «» и «-». Ударный слог слова носителя рематического акцента подчеркивается. О других деталях используемой системы дискурсивной транскрипции см. Кибрик, Подлесская (ред.) 2009. Напомним, что в той версии примера, которая дается по МУРКО, знаки «/», «» имеют другую интерпретацию - там они используются для сегментации на межпаузальные фрагменты.
} 
(16) Как говорил Козьма Прутков/ «зри в корень». [Теория асимметрии мозга. Программа "Гордон" (HTB) (2003)]

Как говорил (...0.6) Козьма /Прутков,

(...0.5)

«/зри в |корень».

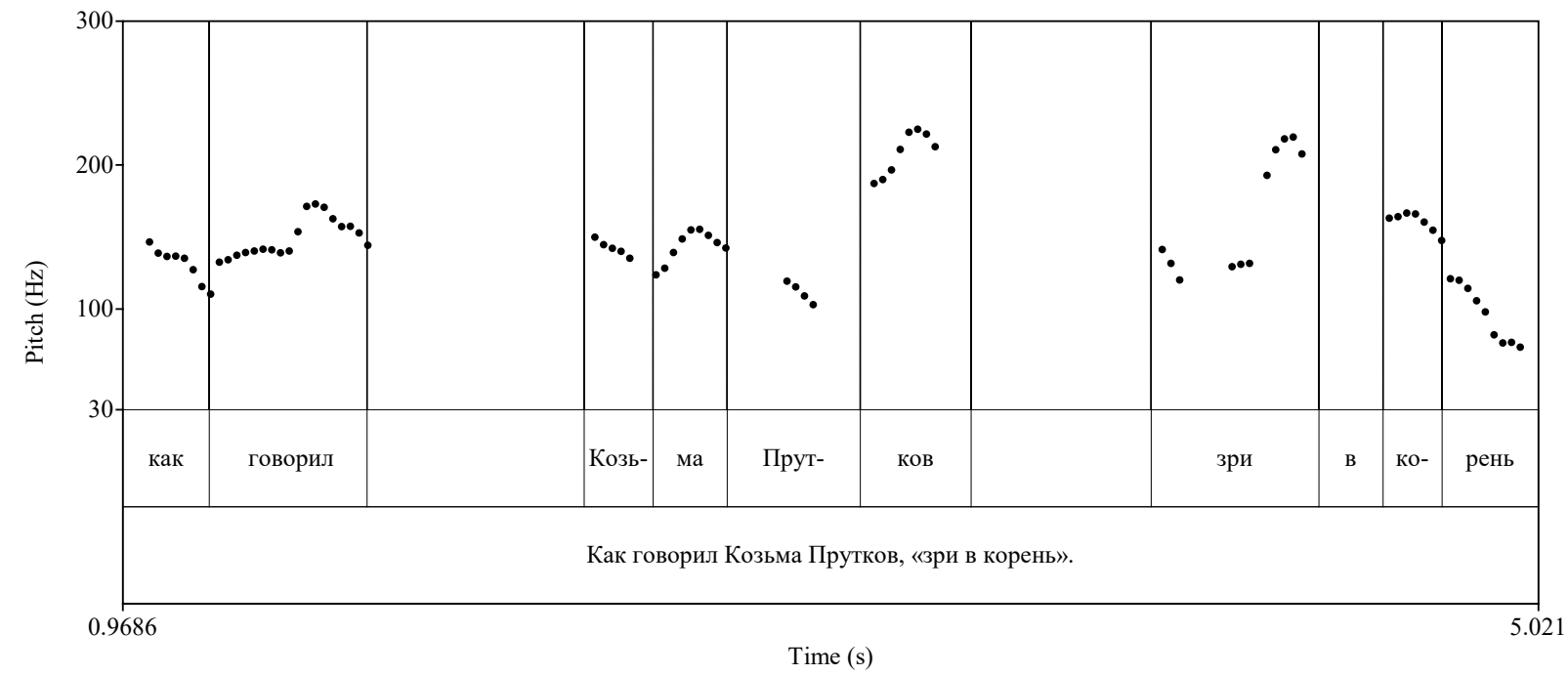

Рисунок 1. Интонограмма к примеру (16)

(17) И особый признак/ на котором бы хотелось остановиться/ это тип значения. Как мы уже сказали чуть раньше/ конечно нам бы хотелось прослеживать модели переносов в разных языках. Однако что мы делали в русской базе? Для каждого значения мы указывали значение/ от которого образовано данное/ и тип перехода. [М. Кюсева. Доклад на конференции «Диалог 2013» (2013) // Из коллекции НКРЯ]

это тип Һзначения.

(..0.4)

Как мы уже Ісказали чуть /раньие,

(..0.1)

конечно нам бы |хотелось прослеживать модели /переносов в разных | языках.

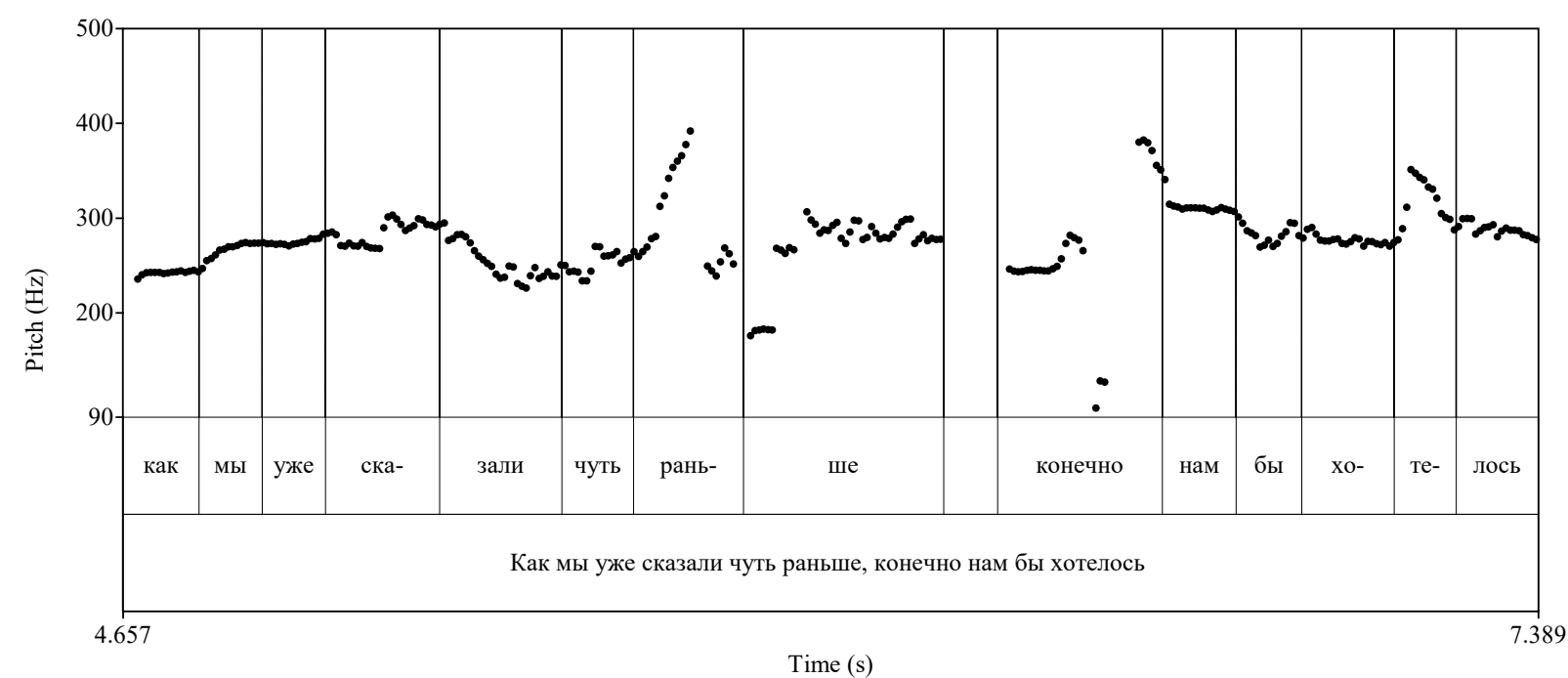

Рисунок 2. Интонограмма к примеру (17) 
Данный паттерн используется в абсолютном начале эпизода или после явно выраженной завершенности предшествующего сегмента. И в (16), и в (17) фразовый акцент в как-фразе расположен на последнем слове. В (16) - это подлежащее (=автор цитаты), здесь действует упоминавшееся выше правило препозиции глагола при подлежащем, выраженным полной именной группой. В (17) подлежащее - личное местоимение, инверсии нет, фразовый акцент локализуется на заключительном обстоятельстве времени. В обоих случаях фразовый акцент реализуется с выраженным подъемом и кумулятивно кодирует рему и незавершенность, т.е. проецирует продолжение дискурса. Эта же просодическая конфигурация может манифестировать и омонимичную коммуникативную структуру, в которой Козьма Прутков и чуть раньше являются носителями узкого (контрастного) фокуса ('Козьма Прутков, а не кто-то другой'; 'раньше, а не сейчас'). При контрасте акцент может сдвигаться внутрь как-фразы с сохранением того же направления движения тона - в данном случае, подъема тона по типу ИКЗ в терминах интонационных конструкций (Брызгунова 1982):

(17)' Как мы уже чуть /раннье сказали....

Если инверсии нет, и у глагола нет распространителей, то типичным акцентоносителем становится финальный глагол, так, у примера (17) легко реконструируется и вариант (17)”:

(17)"ККак мы уже /сказали....

Препозитивные как-фразы с финальным акцентированным глаголом встречаются в МУРКО массово, что не удивительно, учитывая, что в корпусе широко представлены записи докладов и лекций «от первого лица»:

(18) Как я уже сказал/ сочинения лингвистов-любителей чрезвычайно однообразны. [Андрей Зализняк. Что такое любительская лингвистика? Лекиии Полит.ру (2010)]

Препозитивные как-фразы в рассмотренных выше примерах не демонстрируют симптомов просодической редукции, для них характерны выраженные акценты: на рисунках 1 и 2 видно, что подъем тона происходит в существенном интервале - от $100 \mathrm{~Hz}$ до $250 \mathrm{~Hz}$ в (16) и от $250 \mathrm{~Hz}$ до $400 \mathrm{~Hz}$ в (17); по перцептивной оценке, нет увеличения темпа, снижения громкости. Кроме того, препозитивные как-фразы могут иметь внутреннюю коммуникативно-просодическую структуру и, в частности, иметь дополнительные акценты, помимо главного фразового: так, в примере (17) имеется дополнительный акцент на слове сказали, он реализуется с падающим тоном, адаптированным к финальному подъему. В целом, препозитивные как-фразы ведут себя, с точки зрения просодии так же, как прототипические препозитивные обстоятельственные клаузы, для которых характерен тематический статус в составе полипредикатвной конструкции (о возможной интерпретации коммуникативного статуса нефинальных клауз в иллокутивной цепочке, cм. inter alia, Коротаев 2018).

Как мы увидим ниже, правила локализации актентоносителя в как-фразе едины и не зависят от расположения как-фразы относительно цитаты, а вот характер движения тона во фразовом акценте и степень просодической редукции как-фразы, наоборот, весьма чувствительны к ее расположению относительно цитаты.

\section{2 Как-ремарка внутри цитаты}

Рассмотрим пример (19):

(19) Чтобы выполнить свои обещания/ он начинает воевать с Новгородом/ он устраивает жестокий разгром Торжка. То есть тверской князь вёл политику/ как мы бы сказали/ не по средствам/ не по карману. [Николай Борисов. Возвышение Москвы в 14-15 веках. Проект Асадетіа (ГТРК Культура) (2010)]

То есть Ітверской /князь (...0.8) /вёл политику - 
(...0.5)

как-мй бы сказали,

- /не по Ісредствам,

(..0.2)

/не по |карману.

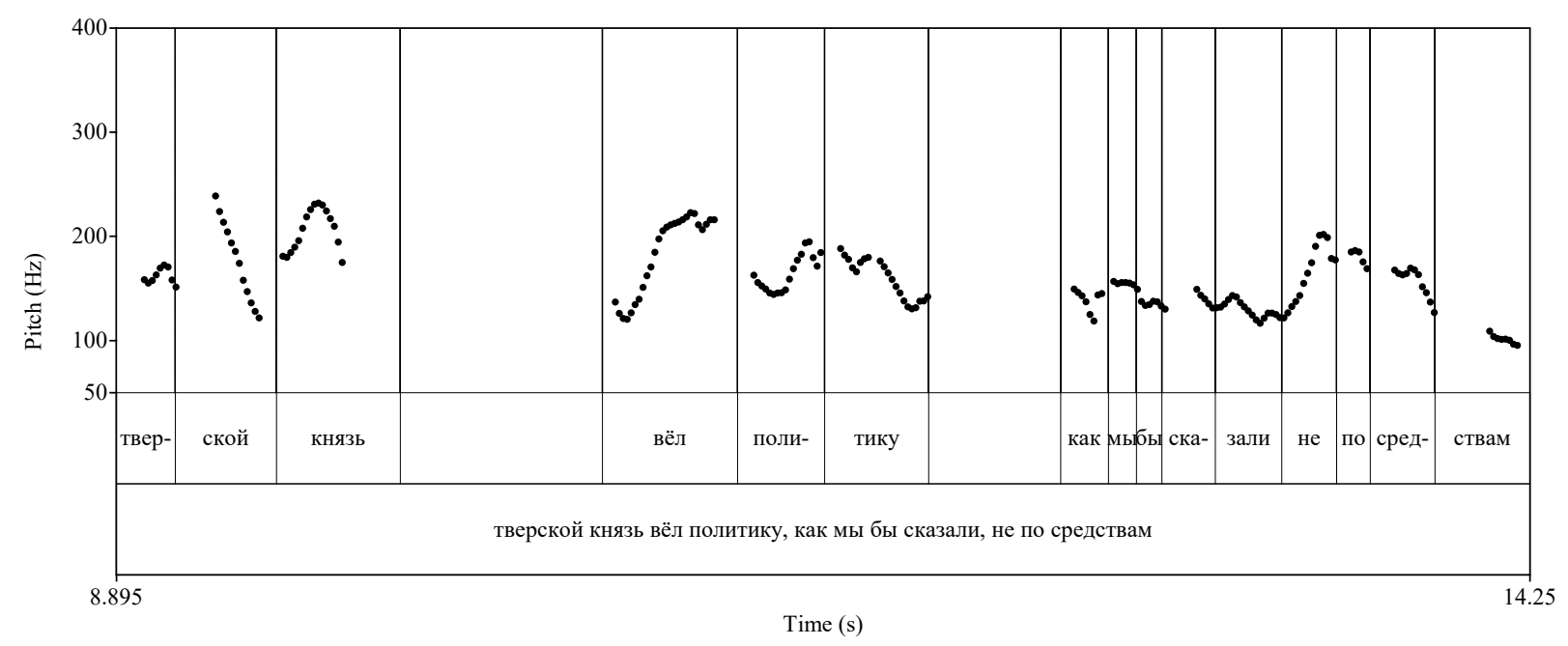

Рисунок 3. Интонограмма к примеру (19)

В данном примере как-фраза оказывается во вставке между последовательностью тем (первая тема тверской князь, вторая - вёл политику) и последовательностью рем (не по средствам, не по карману). Как-фраза демонстрирует характерные признаки просодической редукции перцептивно на слове $\mathbf{M b l}$ можно уловить акцент, но он крайне слабый, движение тона - ровное, вся фраза - в тональном диапазоне существенно более узком, чем фрагменты цитаты слева и справа, произносится в более высоком темпе. Если считать акцент на слове $\mathbf{~} ы$ коммуникативно значимым, то его можно интерпретировать как контрастный ('это мы, в наше время, так говорим, в то время так бы не сказали')

Однако продемонстрированный выше паттерн - не единственно возможный вариант манифестации как-фразы, разрывающей клаузу. Широко представлен в корпусе и другой вариант, при котором в как-фразе просодической парентезы нет, см. (20):

(20) Но второй глобальный элемент этого синтеза - германщы/ на которых мы завершали проильй раз наш разговор/ не были христианами. Конечно/ ни в коей мере/ это были чистые язычники/ у них были свои боги и больше всего связаны с силами природы - это были настоящие/ ну как римляне бы сказали/ дикари/ варвары. [Наталия Басовская. Зарождение средневековой иивилизации Западной Европы. Проект Асаdетіа (ГТРК Культура) (2010)]

/больше всего связаны с силами /-приро-оды,,,

\section{(..0.3)}

это были /настоящие -

$(\ldots 0.5)$

(a 0.5$) / H y$,

$\left(\partial^{2} 0.5\right)$

$(. .0 .3)$

как /римляне бы сказали,

-/-дикари्, ,,

(...0.7)

/-варварыl,,, 


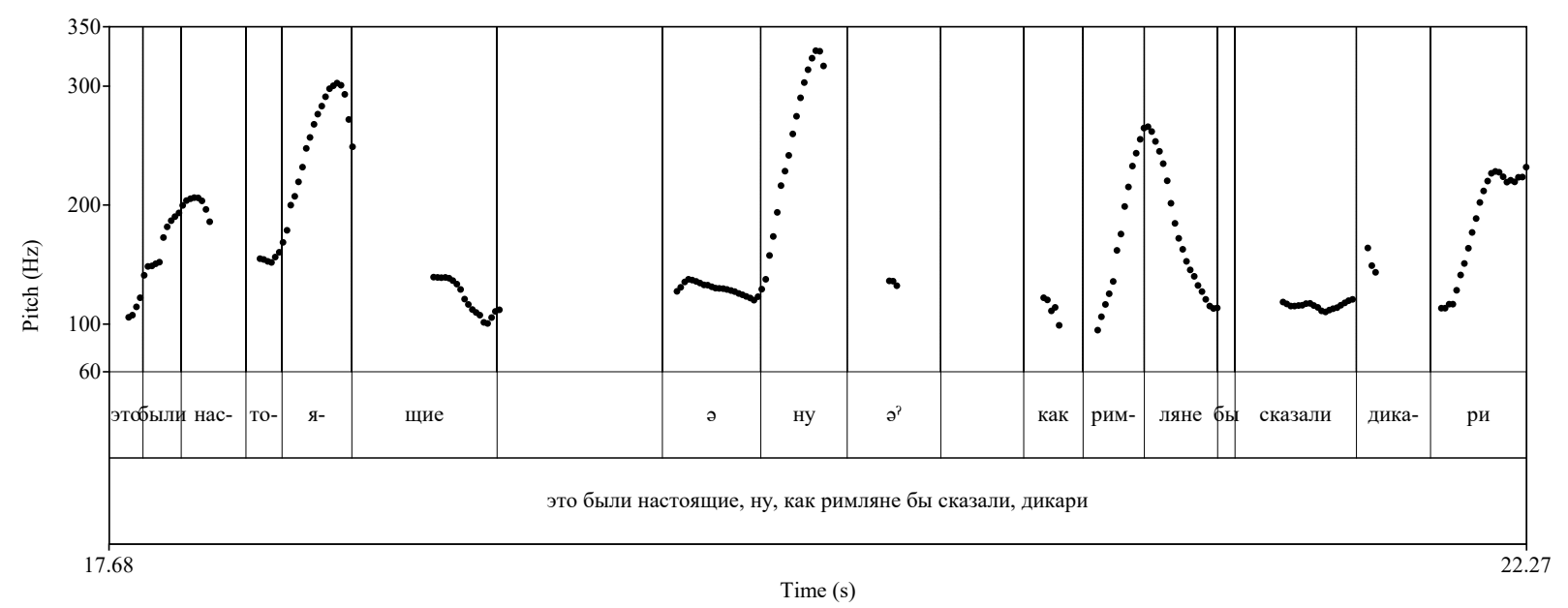

Рисунок 4. Интонограмма к примеру (20)

В примере (20) в как-фразе главный фразовый акцент - на слове римляне; инверсии нет, что объясняется контрастом - римляне противопоставлены современным интерпретаторам, которые не употребляют столь явно оценочных номинаций. Как-фраза «разбивает» сильную внутриклаузальную синтаксическую связь, располагаясь между согласованным определением и определяемым. Однако несмотря на то, что фраза структурно является вставкой, просодических симптомов парентезы не наблюдается: фразовый акцент реализуется с характерным для данной говорящей выраженным подъемом по типу ИК 3 , разница между нижней и верхней точкой составляет около $180 \mathrm{~Hz}$, нет ни ускорения, ни снижения громкости, слова выразительно артикулированы. Как кажется, мы имеем здесь дело с особой коммуникативной стратегией: какфраза намеренно реализуется как просодически незавершенная, проецирующая продолжение, тем самым говорящий демонстрирует, что ядром цитаты (или, сферой действия цитации) является не вся обрамляющая ставку структура, а только та ее часть, которая расположена после как-фразы. В примере (20) имеется дополнительное подтверждение тому, что ядро цитаты расположено после как-ремарки: слова дикари и варвары реализуются с выраженной эмфазой с усилением громкости и особым типом фонации.

\section{3 Как-ремарка после цитаты}

Постпозиция как-ремарки может быть продемонстрирована следующими двумя примерами:

(21) Такие слова/ товарищи/ засоряют наш язык/ наш великий/ могучий/ прекрасный язык/ как сказал Некрасов. [Анатолий Рыбаков, Николай Калинин. Кортик, к/ф (1973)]

наш |великий | могучий |Іпрекрасный/языєк,

(..0.3)

как (..0.1) /сказал |Некрасов. 


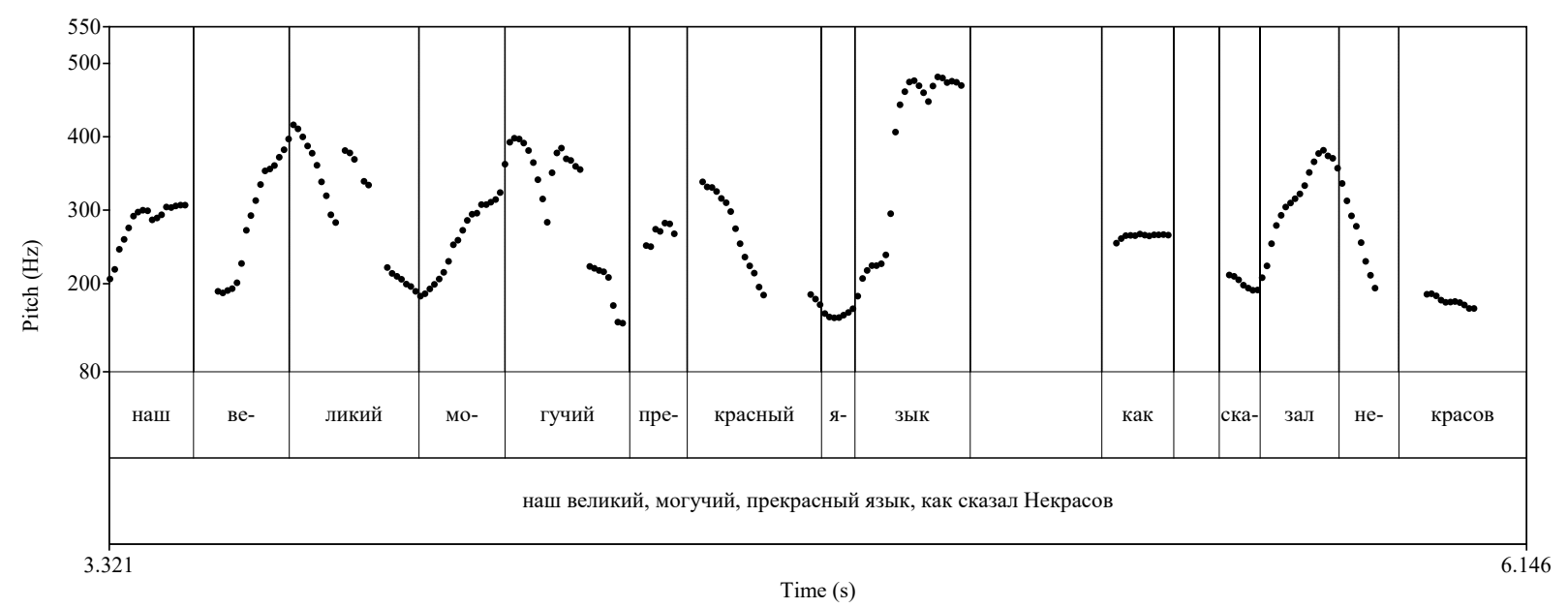

Рисунок 5. Интонограмма к примеру (21)

(22) но мне хотелось бы щуас действительно вернуться к физике. Вот в области магнитных нано-структур/в области суперпарамагнетизма имеет много интересных квантовых эффектов/ где встречаются квантовые и классические закономерности/ как мы сказали. [Суперпарамагнетизм. Программа "Гордон" (НТВ) (2003)]

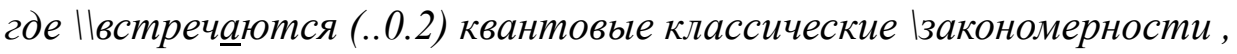
как мы Һсказали.

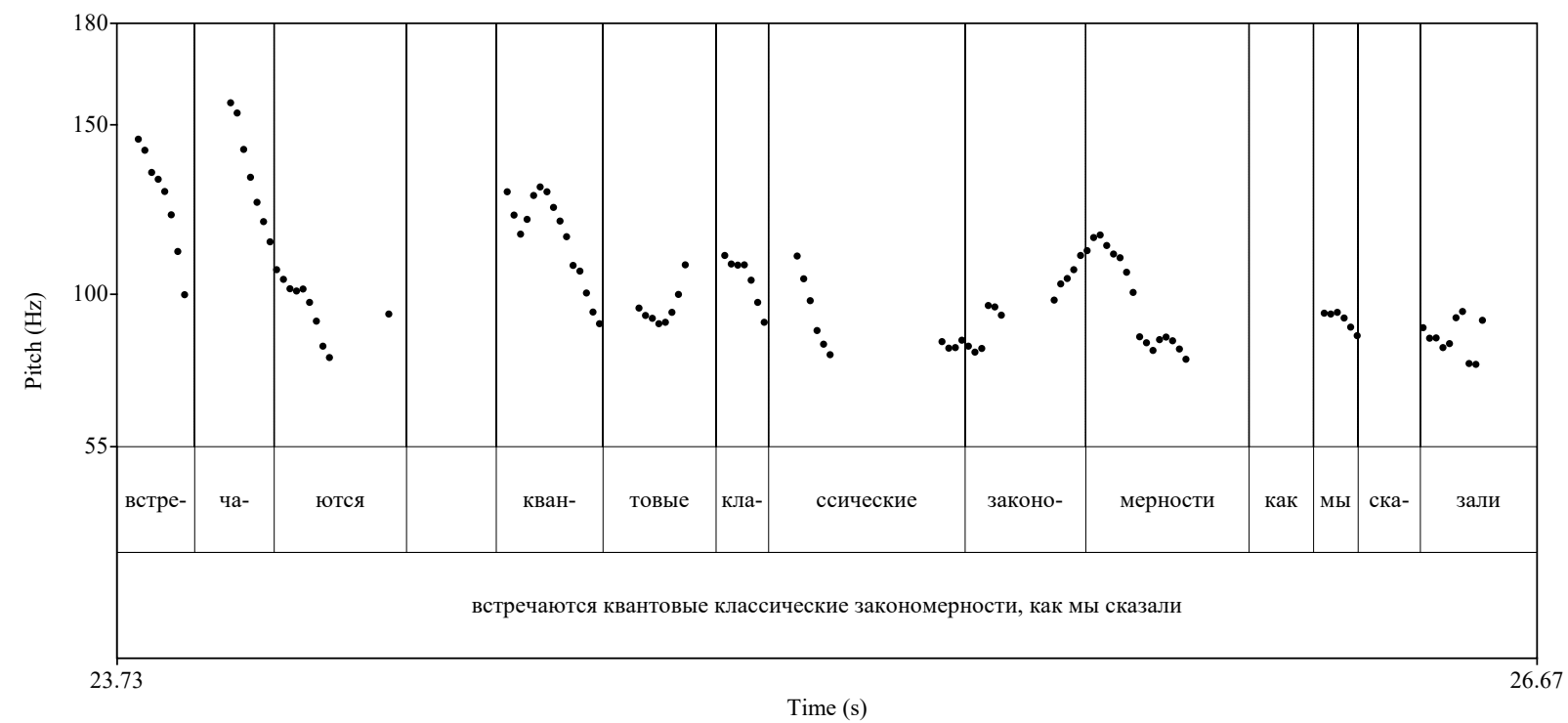

Рисунок 6. Интонограмма к примеру (22)

В (21) постпозитивная как-ремарка не парентетична: носитель фразового акцента - слово Некрасов - произносится с выраженным падением; кроме того, во фразе есть еще один акцент подъем на слове сказал, это движение тона адаптировано к финальному рематическому падению на Некрасов. В цитате, предшествующей как-ремарке, скандирующие падения по типу ИК2 и на слове язык - финальный подъем в очень высокий регистр, проецирующий продолжение дискурса. В (22) напротив, цитата не проецирует продолжения, фразовый акцент - на слове встречаются имеет верификативную функцию и реализуется с резким падением по типу ИК2. Пострематическая часть достаточно длинная, и, возможно, поэтому появляется дополнительный падающий тон на финальном слове закономерности, что подтверждает просодическую завершенность цитаты. В 
этой ситуации, как-ремарка ожидаемо появляется в редуцированном виде - с очень слабым падением на реме сказали, в суженом тональном диапазоне и со сниженной громкостью. Таким образом, в постпозиции к цитате парентеза в авторской ремарке возможна, но не обязательна.

Разумеется, мы вынужденно рассмотрели лишь самые базовые просодические конфигурации с бинарной структурой «цитата + ремарка». В реальном дискурсе реализации как-ремарки чувствительны не только к структуре самой цитационной конструкции, но и к её внешним синтаксическим и, шире, дискурсивным связям. Это дискурсивное разнообразие осталось за пределами данной статьи, однако приведем в порядке иллюстрации один красноречивый пример. Как мы уже писали выше, базовое значение вводно-союзной конструкции - дать отсылку к тексту, который имеется в общей базе знаний коммуникантов; при этом сама эта отсылка становится фоном, на котором говорящий формулирует собственное суждение. В результате, в живой речи часто оказывается, что во вставку помещается не только как-ремарка, но и целиком вся конструкция «цитата + ремарка». Так, в примере (23) во вставке оказывается цитационная конструкция Как говорил Блок, дворяне все родня друг другу: она размещается внутри цепочки характеристик поэта - дружен с декабристами, связан родственными связями, не участвовал в декабристском движении. Единство этой цепочки поддерживается семантической однородностью элементов и их просодической однообразностью - все они реализуются как нефинальные элементы списка (с подъемом тона по типу ИК6 или ИК3). Вставочный характер конструкции приводит к тому, что вся она произносится в сниженном регистре, в диапазоне, существенно суженном по сравнению с основным текстом. При этом препозитивная как-ремарка вовсе лишается акцента, что, как мы видели выше, препозитивным ремаркам в общем случае не свойственно:

(23) Был дружен с декабристами. И связан родственными связями. Как говорил Блок/ дворяне все родня друг другу. И не участвовал в декабристском движении. [Юрий Пивоваров. Русская история в зеркале русской мысли. Проект Асаdетіа (ГТРК Культура) (2010)]

был Џружен с Лдекабристами,,

и связан родственными $\rightarrow$ связями,,,

(4 0.4$)$

(Как говорил Блок дворяне /все? (..0.2) родня друг Ідругу.)

( 40.5$)$

и-ии не Уучаствовал в декабристском /движении,

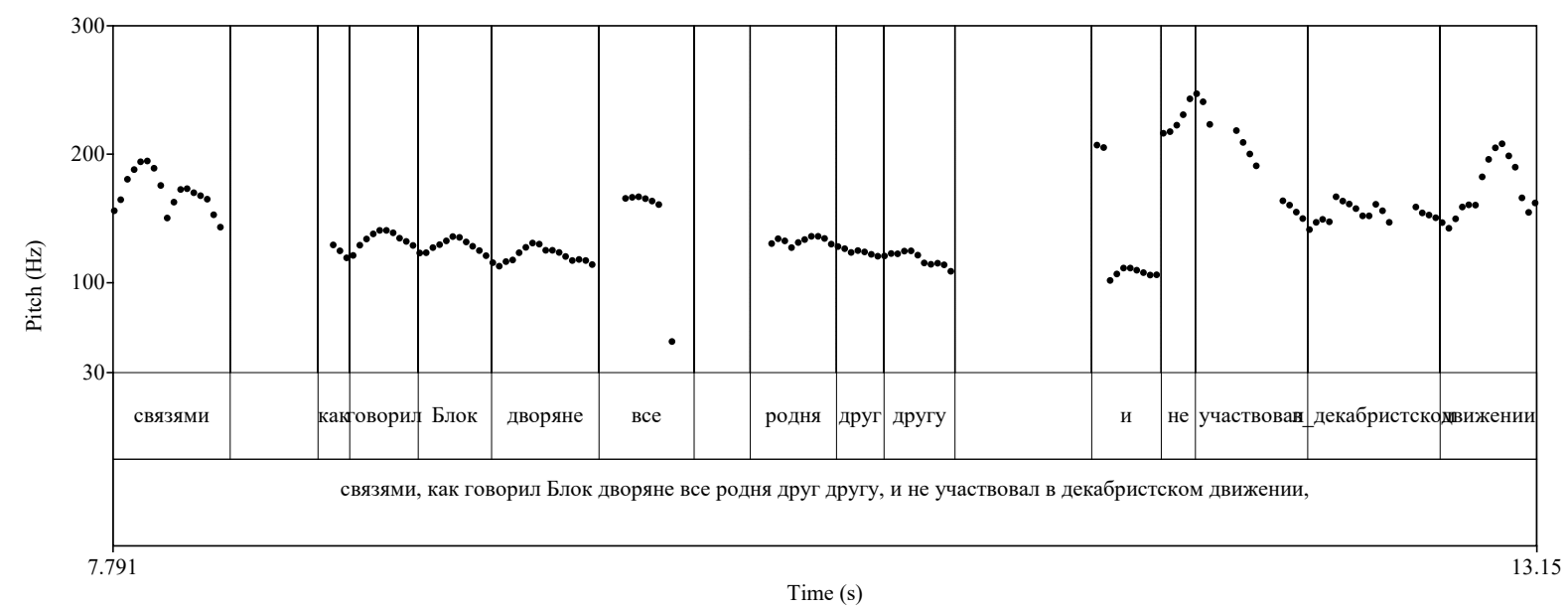

Рисунок 7. Интонограмма к примеру (23)

Сказанное позволяет сделать вывод, что просодическое поведение как-ремарки может быть весьма разнообразным и в зависимости от структурных и дискурсивных условий демонстрировать разную степень просодической редукции - от прототипической парентезы с отсутствием фразовых акцентов, узким тональным диапазоном, высоким темпом и т.П., до полного отсутствия парентетических проявлений. 


\section{5 Итоги}

В богатой литературе по парентезе (см. inter alia Dehé 2010, Schneider 2015 и подробный обзор публикаций там) слова, конструкции и предложения квалифицируются как парентетические (вводные), прежде всего, не по форме, а по функции. Это функция плохо формализуется, но, так или иначе, сводится к признанию их вторичности по отношению к «опорному» высказыванию: они являются вспомогательной, дополнительной ремаркой («interpolated into the current string of the utterance», Dehé 2010:307); их роль в пропозициональном содержании ослаблена (Янко 2003:331), они выведены за пределы текущего речевого акта и фокуса внимания говорящего («Parenthesis enables the speaker to put an item outside the ongoing speech act and, thus, to distance it from the focus of attention of the addressee», Schneider 2015: 281).

Эта функция может манифестироваться в целом ряде эмпирически проверяемых симптомов, некоторые из которых приводятся ниже:

a. Парентеза разрывает текущее высказывание на два фрагмента, между которыми сохраняется тесная связь - синтаксическая или риторическая (дискурсивная)

b. Парентетический фрагмент не формирует узла в синтаксической структуре опорного высказывания.

c. Парентетический фрагмент имеет регуляторный статус (Chafe 1994: 63ff), т.е. используется не для выражения пропозиционального содержания, а для организации и регулирования речевого потока, выражения оценочных значений, привлечения внимания слушающего и т.п.

d. Парентетический фрагмент просодически выделен из опорного высказывания: его границы просодически маркированы, текущие просодические параметры (тоновый диапазон, темп, громкость) отличаются от таковых в опорном высказывании, он не имеет внутреннего коммуникативно-просодического членения.

e. В парентетическом фрагменте имеются ограничения на лексическое многообразие и морфосинтаксис.

Легко убедиться, что каждый их этих признаков в отдельности не проходит теста на необходимость и достаточность. Так, «освященные лингвистической традицией» вводные выражения типа к счастью легко размещаются не только внутри опорного высказывания, но на его левой или правой периферии. Или другой пример - регуляторный дискурсивный маркер вот в значении возврата к временно прерванному эпизоду: согласно (Кибрик, Подлесская (ред.) 2009: 146-152), этот маркер допускает не только просодически автономное употребление - ожидаемое для вводного слова, но и полную интеграцию в опорное высказывание - атоническое произнесение, отсутствие просодических границ с материалом опорного высказывания (ср. также наблюдения о возможной просодической интеграции парентетических фрагментов в английском языке в Dehé 2007). Статус вводных признается за предложениями, которые присоединяются сочинительными и сравнительными союзами, т.е. имеют не типичную для вводных конструкций эксплицитно маркированную коннектором связь с опорным высказыванием, ср. (24) со вводной клаузой, вводимой союзом $a$ (цит. по Подлесская 2018), а также английские and-parentheticals (Kavalova 2007) и упоминавшиеся выше as-parentheticals (Potts 2002, LaCara 2016):

(24) FS_02-f_Sp (корпус «Веселые истории из жизни», spokencorpora.ru)

38. $\cdot(0 . \overline{4} 0)$ И тут он значит /оборачивается,

39. смотрит на одну из кадок с этими /цветами,

40. (а там \кактусов было много,)

41. ‥(0.52) и /говорит,

42. что мол одного кактуса не \хватает.

Рассмотренный нами класс вводно-союзных конструкций с глаголом речи тоже показателен в этом отношении - эти конструкции демонстрируют весьма пестрое проявление симптомов парентезы, они: 
a) могут занимать любую позицию относительно опорной клаузы. причем как-фразы с идентичным лексическим наполнением и грамматической структурой могут менять свойства в зависимости от их позиции относительно цитаты;

b) вводятся сравнительным союзом, т.е. встроены в синтаксическую структуру предложения;

c) имеют прагматически вспомогательную функцию, отсылая к источнику цитаты;

d) неоднородны в просодическом отношении и, в частности, могут произноситься как атонически, так и с выраженной акцентуацией;

е) подвержены частичным ограничениям на порядок слов и грамматическую форму.

Из всего перечисленного только пункты с. и е. безусловно ассоциированы с прототипом парентезы, остальные - плохо вписываются в этот прототип. Эти результаты позволяют предположить, что наиболее плодотворным подходом к описанию парентезы является многофакторный анализ, позволяющий учитывать все многообразие исследуемой зоны и выделять лингвоспецифические кластеры значений релевантных параметров. Таким образом, наше исследование, с одной стороны, имеет дескриптивное значение: на основе корпусных данных оно уточняет наше представление о важном сегменте русской грамматики. С другой стороны, оно позволяет ввести данные русского языка в оборот исследований по кросс-языковой вариативности парентетических конструкций и, тем самым, может иметь теоретическое и типологическое значение.

\section{Литература}

[1] Boersma, Paul \& Weenink, David. Praat: doing phonetics by computer [Computer program]. Version 6.1.38, 2021. Access mode: http://www.praat.org/

[2] Bryzgunova E. A. Intonation [Intonatsiya], Russian Grammar [Russkaja grammatika]. Vol. 1, Nauka, Moscow, 1982. - P. 98-118.

[3] Chafe, Wallace. Discourse, consciousness, and time. Chicago: University of Chicago Press, 1994.

[4] Cristofaro, SoniaSubordination. (Oxford Studies in Typology and Linguistic Theory.) Oxford: Oxford University Press, 2003.

[5] Dehé, Nicole. Parentheticals // Cummings, Louise (ed.) The Routledge Pragmatics Encyclopedia. Routledge, 2010. - P. 307-308.

[6] Dehé, Nicole. The relation between syntactic and prosodic parenthesis // Dehé, N., Kavalova, Y. (eds.) Parentheticals (Linguistik aktuell/ Linguisticstoday 106), Amsterdam: John Benjamins, 2007. — P. 261-284.

[7] Janko T. E. Kommunikativnye strategii russkoj rechi [Communicative strategies in spoken Russian]. Moskva: Jazyki Slavjanskix Kul'tur, 2001.

[8] Kibrik A. A., Podlesskaya V. I. [Eds.] Rasskazy o snovidenijax: korpusnoe issledovanie usntogo russkogo diskursa [Night Dream Stories: A corpus study of spoken Russian discourse]. Moscow: Jazyki Slavjanskix Kul'tur, 2009.

[9] Kavalova, Yordanka. And-parenthetical clauses. In Nicole Dehé, Yordanka Kavalova (eds.). Parentheticals. Amsterdam - Philadelphia: Benjamins, 2007. - P. 145-172.

[10] Korotaev, N.A. How Intonation Structures Spoken Narratives: Non-final Phase Contexts // Computational Linguistics and Intellectual Technologies Papers from the Annual International Conference "Dialogue" (2018). Issue 17, 2018. - P. 342-355.

[11] Kustova, Galina. Sistemnye svjazi prisoedinitel'nyx i parentetičeskix konstrukcij [Systemic relations in parcellated and parenthetical constructions] // International conference "Problematic questions in Functional Grammar": In commemoration of A.V.Bondarko 90-th anniversary. Abstracts. St.Petersburg: Institute for Linguistic Studies, Russian Academy of Sciences, 2020. - P. 18.

[12] LaCara, Nicholas J. Anaphora, Inversion, and Focus". Doctoral Dissertations. 746. - 2016 - Access mode: https://scholarworks.umass.edu/dissertations 2/746

[13] Lehmann Christian. Towards a typology of clause linkage // Haiman, John and Thompson, Sandra A. (eds.) Clause combining in grammar and discourse. Amsterdam: John Benjamins, 1988. — P. 181-225

[14] Paducheva E.V. Semanticheskie issledovaniya [Semantic studies]: Semantika vremeni i vida v russkom yazyke [Semantics of tense and aspect in Russian]. Semantika narrativa [Semantics of narrative]. M: Shk. «Yazyki russkoj kul'tury», 1996

[15] Podlesskaya V. "A u nas v kvartire gaz. A u vas?": the Russian Conjunction A viewed through the Prism of Prosodically Annotated Corpus Data // Computational Linguistics and Intellectual Technologies: Papers from the Annual International Conference "Dialogue" Issue 17 (23), Moscow: RSUH, 2018. — P. 601-618. 
[16] Potts, Christopher. The syntax and semantics of as-parentheticals // Natural Language \& Linguistic Theory 20, 2002. - P. 623-689.

[17] Schneider, Stefan..Parenthesis: Fundamental features, meanings, discourse functions and ellipsis // Kluck, Marlies; Ott, Dennis; Mark de Vries (eds.) Parenthesis and Ellipsis [Studies in Generative Grammar, Volume 121], De Gruyter Mouton, 2015. - P. 277-300.

[18] Брызгунова Е. А. Интонация, Русская грамматика, том 1, М.: Наука, 1982. — Р. 103-118.

[19] Кибрик А.А., Подлесская В.И. (ред.) Рассказы о сновидениях: Корпусное исследование устного русского дискурса. М.: ЯСК, 2009.

[20] Коротаев Н. А. Интонационная структура устного рассказа в контексте незавершенности // Компьютерная лингвистика и интеллектуальные технологии: По материалам ежегодной международной конференции «Диалог», Вып. 17(24), 2018. - Р. 342-355.

[21] Кустова Г.И. Системные связи присоединительных и парентетических конструкций // Международная конференция «Актуальные проблемы функциональной грамматики», посвященная 90-летию со дня рождения А. В. Бондарко. Тезисы докладов. СПб: Институт лингвистических исследований РАН, 2020.

[22] Падучева Е.В. Семантические исследования: Семантика времени и вида в русском языке. Семантика нарратива. М: Шк. "Языки русской культуры", 1996

[23] Подлесская В.И. «А у нас в квартире газ! А у вас?»: конструкции с союзом А по данным просодически размеченного корпуса // Компьютерная лингвистика и интеллектуальные технологии: По материалам ежегодной Международной конференции «Диалог». Вып. 17 (23), М.: Изд-во РГГУ, 2018. — Р. 601-618.

[24] Янко Т. Е. Коммуникативные стратегии русской речи. Москва: Языки славянских культур, 2001. 